Relations

RELQTIONS

\title{
Ressources documentaires
}

Numéro 782, janvier-février 2016

URI : https://id.erudit.org/iderudit/80024ac

Aller au sommaire du numéro

Éditeur(s)

Centre justice et foi

ISSN

0034-3781 (imprimé)

1929-3097 (numérique)

Découvrir la revue

Citer ce compte rendu

(2016). Compte rendu de [Ressources documentaires]. Relations, (782), 49-49.

Ce document est protégé par la loi sur le droit d'auteur. L'utilisation des services d'Érudit (y compris la reproduction) est assujettie à sa politique d'utilisation que vous pouvez consulter en ligne.

https://apropos.erudit.org/fr/usagers/politique-dutilisation/
Cet article est diffusé et préservé par Érudit.

Érudit est un consortium interuniversitaire sans but lucratif composé de l’Université de Montréal, l'Université Laval et l'Université du Québec à Montréal. Il a pour mission la promotion et la valorisation de la recherche. https://www.erudit.org/fr/ 


\section{La mémoire vivante de Relations}

\footnotetext{
(4) I'occasion de son $75^{e}$ anniversaire, Relations fait son entrée dans la collection numérique de revues et journaux québécois de Bibliothèque et Archives nationales du Québec (BAnQ). Accessible par son portail Web (<banq.qc.ca>), il s'agit d'une des collections patrimoniales de l'institution qui regroupe plus de 180 titres témoignant notamment de la vie intellectuelle, politique et culturelle du Québec tout au long de son histoire.
}

précieuses archives, mais bien une solide réanimation qui leur donnera une seconde vie. Le travail de numérisation mené par BAnQ donne en effet un accès inédit au contenu intégral de près de 75 ans d'articles sur une multitude de sujets, à travers une interface de consultation simple et somme toute conviviale.

Celle-ci permet d'abord de consulter les anciens numéros un à la fois, par année de publication, ce qui convient si l'on souhaite explorer l'important corpus en curieux, un peu comme on bouquine. Au hasard de ses intérêts personnels, on pourra alors tomber sur certains des doute la qualité de l'indexation des fichiers et l'outil de recherche en texte intégral, qui permettent de faire une lecture transversale du riche corpus en repérant des auteurs, des mots-clés ou des récurrences thématiques. Ces outils sont très utiles notamment pour les chercheurs qui s'intéresseraient, par exemple, au traitement d'un sujet précis au fil du temps ou à déceler les courants de fond qui traversent la revue de ses débuts jusqu'à aujourd'hui. C'est ainsi tout un pan du christianisme social au Québec qu'il est désormais possible d'interroger et de réinterpréter, le tout à l'aide d'outils facilitant grandement

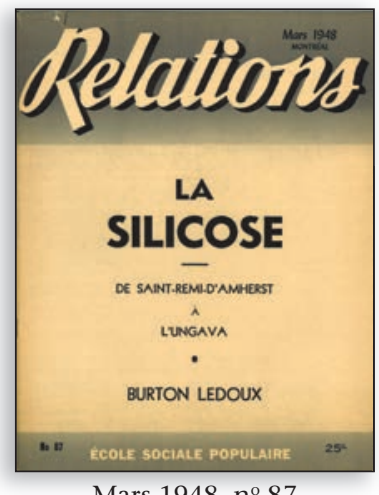

Mars 1948, $\mathrm{n}^{\circ} 87$
Octobre 1962, n 262

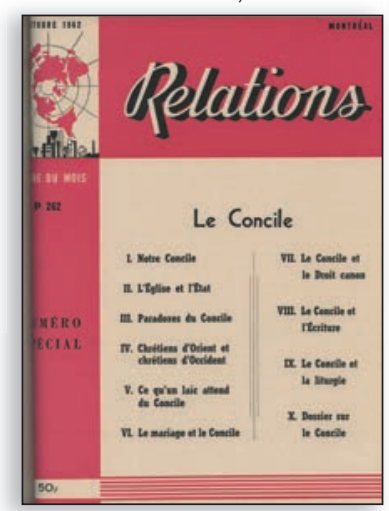

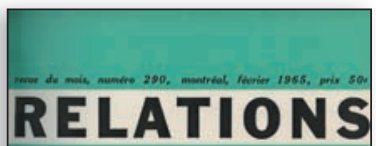

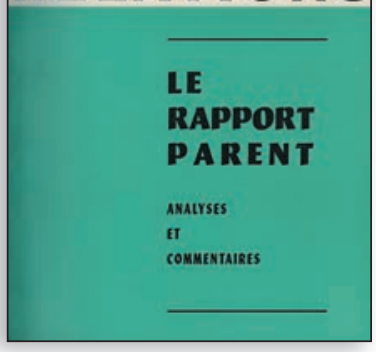

Février 1965, nº 290

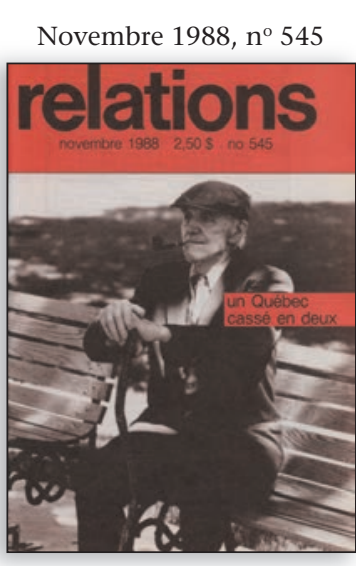

ReLations La force

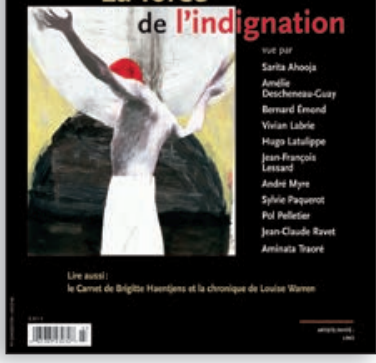

Mars 2011, nº 747
Les quelque 760 numéros de Relations publiés entre 1941 et 2012 (les archives des trois dernières années étant réservées aux abonnés de la revue) viennent donc enrichir cette importante collection qui comprend des titres emblématiques comme L'Action nationale, Parti pris, La vie en rose, Cité libre ou Vie ouvrière. Autant de publications qui, comme Relations, sont à la fois des morceaux de I'histoire du Québec et ont contribué à la façonner.

L'intronisation au panthéon de la mémoire collective - fût-il numérique éveille toujours des sentiments un peu ambigus. L'impression qu'on momifie une œuvre n'est jamais bien loin, surtout lorsqu'il s'agit d'une œuvre qui s'écrit au présent et, comme c'est le cas pour Relations, toujours avec fougue malgré l'âge vénérable.

Dans le cas qui nous concerne toutefois, ce n'est pas l'équivalent d'un embaumement rituel que l'on pratique sur ces nombreux numéros qui ont fait époque. Mentionnons, pour n'en citer que quelques-uns, celui de mars 1948 sur la silicose - qui a contribué à éveiller la population aux conditions de travail misérables dans les mines du Québec -, ou encore la série de cinq dossiers « Le Québec cassé en deux » (1988-1994) qui a souligné la fracture sociale existant toujours à plusieurs niveaux dans la société québécoise, en particulier entre les régions et les centres urbains. Le format de numérisation (pdf) permet par ailleurs de voir l'évolution de l'aspect visuel de la revue, dont les variations reflètent aussi les partis pris. C'est particulièrement le cas depuis que la revue a choisi d'accorder une place plus grande aux artistes, dès les années 2000, en résistance à cet air du temps utilitariste qui réduit le monde à sa seule dimension fonctionnelle.

Un des principaux attraits de la plateforme de consultation, toutefois, est sans le travail de construction d'une mémoire vivante qui est celle de Relations, mais aussi celle de la société québécoise.

Cette banque de connaissances que $\mathrm{BAnQ}$ met à la disposition du public est par ailleurs un complément précieux à l'exposition «Relations, une revue engagée dans son époque », qui sera présentée du 7 mars au 21 avril à la bibliothèque centrale de I'UQAM dans le cadre du 75 anniversaire de la revue. Cette exposition montrera le souci constant des artisans de Relations, à travers les époques, d'œuvrer au cœur du monde à la construction d'une société juste et solidaire, accompagnant les luttes sociales et nourrissant la réflexion. Une multitude de dossiers et d'articles ont été passés en revue pour élaborer cette exposition, sans qu'il soit possible de tous les révéler aux visiteurs. Grâce à BAnQ, ces derniers pourront toutefois y accéder en quelques clics.

Emiliano Arpin-Simonetti 